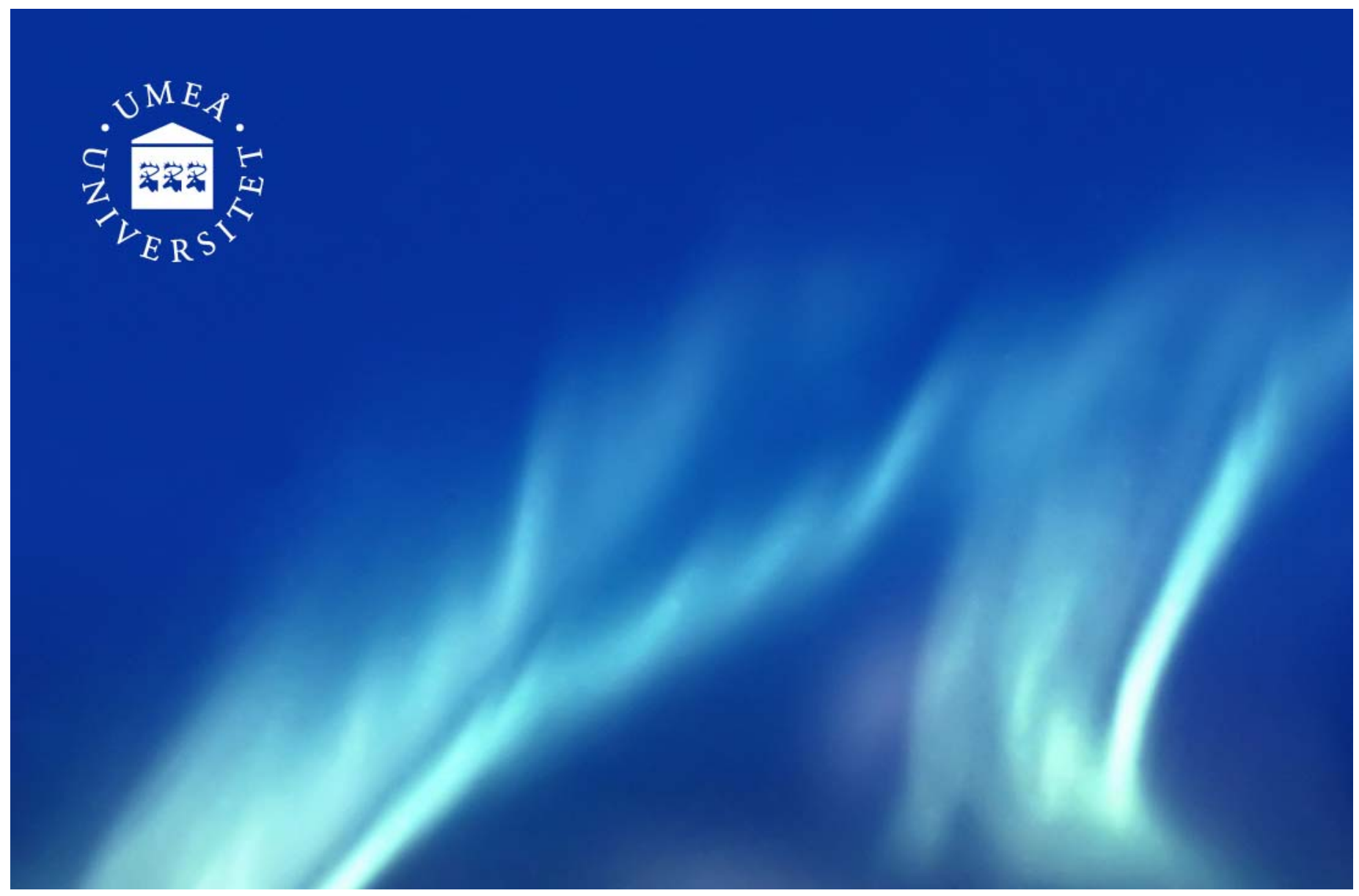

DiVA - Digitala Vetenskapliga Arkivet http://umu.diva-portal.org

This is an author produced version of a paper published in Journal of ASTM International.

This paper has been peer-reviewed but does not include the final publisher proof-corrections or journal pagination.

Citation for the published paper:

Olle Nygren, Roger Lindahl

Development of a method for screening spill and leakage of antibiotics on surfaces based on wipe sampling and HPLC-MS/MS analysis

Journal of ASTM International, 2011, Vol. 8, Issue 6

URL: http://dx.doi.org/10.1520/JAI103544

Access to the published version may require subscription. Published with permission from ASTM International. 


\title{
Development of a method for screening spill and leakage of antibiotics on surfaces based on wipe sampling and HPLC-MS/MS analysis
}

Olle Nygren ${ }^{1}$ and Roger Lindahl

Chemical Occupational Hygiene Group, Environmental and Biogeochemistry, Department of Chemistry, Umeå University, SE-901 87 Umeå, Sweden, e-mail: olle.nygren@ chem.umu.se

\begin{abstract}
A screening method for determination of spill and leakage of twelve different antibiotic substances has been developed. The method is based on wipe sampling where the sampling procedure has been simplified for screening purposes. After sample processing, the antibiotic substances are determined by liquid chromatography coupled to tandem mass spectrometry (HPLC-MS/MS). Twelve antibiotic substances can be determined in the screening method: Cefadroxil, Cefalexin, Ciprofloxacin, Demeclocyklin $\mathrm{HCl}$, Diaveridin, Doxycyklin, Enrofloxacin, Flukonazol, Metronidazol, Norfloxacin, Ofloxacin and Trimetoprim. These substances are active components in antibiotic drugs frequently used in Sweden. For screening investigations using collection of wipe samples, good or acceptable performance was obtained for ten substances on three or more surface materials. Although not fully acceptable, useful performance for screening purposes was also obtained on the other surface materials and for the other substances, except Demeclocyklin $\mathrm{HCl}$, on all surface materials. By employing a classification procedure, where the samples are divided into groups according to increasing contamination of the sample surfaces, screening samples and the contamination level can simply be compared. This classification procedure will also help to circumvent any deficiency in recovery performance for some substances and surface materials.
\end{abstract}

\section{Key words}

Antibiotics, HPLC-MS/MS, leakage, occupational exposure, screening, spill, surface contamination, wipe sampling

\footnotetext{
${ }^{1}$ Corresponding author
} 


\section{Introduction}

Undesired spill and leakage can occur during handling of drugs in hospitals and the medical staff may be occupationally exposed to these drugs. During the past fifteen years, several studies have been published with focus on monitoring spills and leakage as well as occupational exposure to antineoplastic drugs. Dr Tom Connor at the National Institute for Occupational Safety and Health (NIOSH) in the US has compiled a web-based comprehensive database of such literature [1]. Since the handling of antineoplastic drugs may cause exposure, work with these drugs is consequently strictly regulated in most countries [25]. Although each country has their own provisions, they all have a common core of regulations, i.e., all handling should be carried out in safety boxes, isolators or using closed systems, protective clothes shall be worn, special cleaning routines shall be implemented, waste shall be handled as hazardous waste, the compounding systems shall be leak-tested on a regular basis, the staff shall receive adequate education for their work, etc.

Antibiotics belong to another heterogenic group of drugs that is frequently used. In Sweden, more than 140 times more antibiotics are administered to hospital patients, compared to antineoplastic drugs [6]. Moreover, there are only limited regulations for safe handling of antibiotics in medical care, compared to antineoplastic drugs. It is therefore realistic to assume that the spill and leakage of antibiotics is the same or larger than with antineoplastic drugs. There are, however, almost no studies on spill and leakage of antibiotics in medical care.

To carry out relevant studies, there is a need for adequate screening methods to monitor spill and leakage of antibiotics at low levels. There are no methods available for such screening studies. Reversed phase liquid chromatography coupled with mass spectrometry (HPLC-MS) has, however, frequently been used for determination of many antibiotic substances in sewers and waste waters [7-8]. Similar methods have also been developed for screening spill and leakage of antineoplastic drugs. These latter screening methods are frequently based on wipe sampling followed by gas chromatography-mass spectrometry (GC-MS) [9], liquid chromatography-tandem mass spectrometry (HPLC-MS/MS) [10-12], or voltammetry [13-14] (see Ref 1 for more references).

The aim of this study has been to develop and validate a screening method for antibiotic substances taking its basics from a previously developed method for determination of cyclophosphamide (CP) and ifosfamide (iF), based on wipe sampling followed by an HPLC- 
MS/MS analysis [11,15-16] of the samples. The method will be validated for screening a large number of substances used as active components in frequently used antibiotics in wipe samples collected from various frequently occurring surface materials.

\section{Material and methods}

\section{Material and chemicals}

All chemicals were of analytical grade or higher quality and the water was purified in a MilliQ water purifier (Millipore Corp., Billerica, MA, US). Table 1 shows the antibiotic substances that were considered for the method, with trivial names according to FASS [17]. A total of 26 different substances were investigated. Twelve of the investigated substances were found to be possible to analyze simultaneously. These substances are presented in Figure 1, with trivial and chemical names and structural formulas according to FASS [17]. As internal standards, the following isotope-labeled substances were used: Enrofloxacin-D5 (Sigma-Aldrich, Seelze, Germany), $5.5 \mu \mathrm{g} / \mathrm{mL}$ in methanol, and Flukonazol-D4 (CDN Isotopes, Pointe-Claire, Canada), $4.8 \mu \mathrm{g} / \mathrm{mL}$ in methanol.

A wipe sampling tissue (Apoliva, Apoteket AB, Stockholm, Sweden), previously used and tested for antineoplastic materials [15-16], was employed for collecting wipe samples. The Apoliva tissue is a commercial wet tissue single packed in envelopes. It is a nonwoven cellulose fiber tissue $(17 \times 22 \mathrm{~cm})$ wetted with $3.2 \mathrm{~g}$ of a $15 \%$ ethanol in water solution with sorbic acid as preservative. The samples were stored in $15 \mathrm{~mL}$ screw capped plastic test tubes (Sarstedt, Nümbrecht, Germany). Powder-free disposal gloves were used when taking samples.

In the sampling efficiency tests, some frequently occurring surface materials were tested. The following four materials were included in the test: a square of standard window glass $(3 \times 600$ x $600 \mathrm{~mm})$, a square $(600 \times 600 \mathrm{~mm})$ from a PVC homogene plastic floor carpet roll (Armstrong, Holmsund, Sweden), a square (1.25 x $600 \times 600 \mathrm{~mm}$ ) of a stainless steel sheet used for sinks (18/8 steel SS2332),a square $(600 \times 600 \mathrm{~mm})$ from a standard laminate bench top with a melamine surface. 


\section{Instrumentation}

A Perkin Elmer (Norwalk, CT, USA) chromatographic system (HPLC) consisting of two micro-pumps and an auto-sampler (Perkin Elmer series 200) was used for the analysis. The HPLC was equipped with an YMC Hydrosphere C18 column, $5 \mu \mathrm{m}, 150 x 4.6 \mathrm{~mm}$ id, (YMC, INC., Wilmington, NC, US). Acetonitrile in water, with $0.1 \%$ of formic acid, was used as eluent, starting at $15 \%$ acetonitrile for 2 minutes followed by a gradient up to $70 \%$ acetonitrile after 12 minutes. The HPLC system was then reset to $15 \%$ acetonitrile and equilibrated for 8 min between each run. The eluent flow rate was $0.3 \mathrm{~mL} / \mathrm{min}$. The HPLC system was coupled to a tandem mass spectrometer (MS/MS) with a triple quadrupole (API 2000 PE Biosystem, Foster City, CA, USA) equipped with an electrospray ion source (TurboIonSpray). The ion spray voltage (IS) was set to $5.5 \mathrm{kV}$ (positive mode) and the drying gas (TEM) was at $350{ }^{\circ} \mathrm{C}$. Other fixed parameters were Cur (curtain gas) 20, CAD (collision gas) 5, GS1 (ion source gas 1) 20 and GS2 (ion source gas 2) 50. Table 2 shows the component specific MS/MS settings for the twelve antibiotic substances.

\section{Wipe sampling procedure}

Wipe samples were collected on defined areas on the selected surfaces using a wet tissue and disposal gloves. The gloves were changed between each sample to avoid cross-contamination between samples. A homemade plastic frame, encompassing $10 \times 10 \mathrm{~cm}\left(=100 \mathrm{~cm}^{2}\right)$, was used to sample a reproducible area on flat surfaces [15-16]. In case of collecting a wipe sample from a non-flat surface, the size of the area had to be carefully measured after sampling.

The tissue was taken out from the package and cut in half. One half was used for collecting the wipe sample and the other half to clean the plastic frame after sampling to avoid crosscontamination between samples. A special wipe pattern was employed to collect the sample [15-16]. The tissue part with the collected sample was folded and placed into a screw-capped test tube and stored in freezer prior to analysis. 


\section{Sample preparation procedure}

After the samples were thawed, the wipe tissue was pushed to the bottom of the tube using disposable stick. Then, $5 \mathrm{~mL}$ ethanol and $100 \mu \mathrm{L}$ of each internal standard solution were added to the tubes and the samples were shaken for $60 \mathrm{~min}$ (IKA-Vibrax WXR, Labassco, Stockholm). A 1.5-mL aliquot of the sample solutions was withdrawn and transferred to micro-vials and evaporated almost to dryness in a Speed Vac Concentrator (Savant Instruments Inc., Farmingdale, USA), to avoid decreased recovery, possibly due to analyte decomposition or volatilization. The samples were then re-dissolved in $100 \mu \mathrm{L} 5 \%$ methanol in water and transferred to HPLC vials after 30 minutes.

The samples were then analyzed using HPLC-MS/MS. Quantitative determination of the twelve selected antibiotic substances in the samples was obtained using external standards and could be achieved in one run of each sample. The internal standard was used to verify the sample preparation procedure. Quantification was achieved based on the relative response ratio of the MS/MS daughter ion signal between the external standard and each analyte.

\section{Validation of the screening method}

A large number of antibiotic substances were considered for the screening method. A survey was used to document frequently used antibiotics [18]. FASS [17] was used to identify the active substances in these drugs. The investigated substances are listed in Table 1. The aim was to find an analytical method where a large number of antibiotic substances could be adequately determined in the same analysis. Previous studies of spill and leakage of cytostatics [1] have shown that a surface detection limit (SDL) at least in the level of $0.05 \mathrm{ng} / \mathrm{cm}^{2}$ would be desired for a screening method.

For a method intended for supervisory screening, other performance criteria, such as simplicity, robustness and high sampling efficiency, also have high priority. This means that the same analytical performance, as for regular analytical methods, cannot be expected to be obtained. The primary criteria to validate the method as useful were to determine as many substances as possible in the same analysis and at a SDL at $0.05 \mathrm{ng} / \mathrm{cm}^{2}$ or lower. The described screening method has been validated in this context. 
The analytical method was validated using spiked samples. Unused wet tissues (cut in half) were placed in screw-capped test tubes. A $100 \mu \mathrm{L}$ aliquot of a standard solution mixture with different antibiotic substances corresponding to $40-300 \mathrm{ng} / \mathrm{sample}$ was pipetted into each test tube using a micropipette (Finnpipette, Labsystems, Helsinki, Finland). The test samples were then treated according to the sample pre-treatment procedure prior to analysis. The substances that could be analyzed simultaneously with adequate chromatography, MSresolution and with the desired detection limit were selected for further validation of the screening method.

The sampling efficiency from the surface materials was also investigated. A mixed standard solution with all selected substances was prepared in methanol. This solution was spiked onto each surface material in triplicate. Each spiking, $100 \mu \mathrm{L}$, was pipetted using a micropipette (Finnpipette, Labsystems, Helsinki, Finland) to $100 \mathrm{~cm}^{2}$ areas marked up on each surface material. The spikings were left until the surfaces were visibly dried. Wipe samples were then collected from each spiked area using a wipe tissue and a plastic frame [15-16] to wipe a reproducible surface area size. The test wipe samples were then treated according to the sample pre-treatment procedure prior to analysis. The spiking experiment was repeated at a later occasion, giving two sets of triplicate spiking at surface concentrations in the range of $0.4-3 \mathrm{ng} / \mathrm{cm}^{2}$ for the different substances.

\section{Results and discussions}

\section{HPLC-MS/MS analysis}

The previously developed HPLC-MS/MS method for determination of CP [11] was investigated for the analysis of various antibiotic substances. A similar method has also been presented for determination of antibiotics in sewage waters [7]. Reversed phase HPLC coupled with mass spectrometry has frequently been used for determination of many antibiotic substances [7-8]. It was therefore considered to be efficient to employ reversed phase HPLC for the separation of antibiotic substances.

In the separation of complex mixtures of substances, the use of MS/MS for determination of the substances increases the selectivity as well as the specificity for the individual substances. Many interferences from the sample matrix can be eliminated and improve the method 
performance. In the optimization of the MS/MS determination, focus was put on the possibility of determining as many substances as possible in one analysis with adequate sensitivity. The initial MS/MS scan parameters were used to analyze the first nine substances Cefadroxil (m/z 364 and 208), Diaveridin (m/z 261 and 245), Trimetoprim (m/z 291 and 230), Cefalexin (m/z 348 and 158), Ofloxacin (m/z 362 and 318), Norfloxacin (m/z 320 and 276) and Metronidazol (m/z 172 and 154), Ciprofloxacin (m/z 332 and 288), Enrofloxacin (m/z 360 and 316). At $7 \mathrm{~min}$ and $45 \mathrm{~s}$, the scan parameters were changed to analyze the remaining three substances Demeklocyklin $\mathrm{HCl}$ (m/z 465 and 448), Doxycyklin (m/z 445 and 428), and Flukonazol (m/z 307 and 220).. This change of scan parameters increased the sensitivity of all substances.

A mixed external standard solution was used for quantification. Two isotope-labeled substances, Enrofloxacin-D5, and Flukonazol-D4, were initially used as internal standards to verify the quantification of the detected substances in the samples as initial tests showed no decomposition of these compounds. However, later experiments showed that some decomposition of the Enrofloxacin-D5 could occur and lead to falsely high recoveries and an increased variability when using that internal standard for quantification. No significant decomposition was found for Flukonazol-D4. Flukonazol-D4 was therefore used in all calculations although both internal standards were added.

\section{Selection of antibiotic substances}

Based on the antibiotic substances identified in a survey [18], carried out at Swedish hospitals, 27 antibiotic substances were considered for the screening method. To evaluate the possibility for simultaneous HPLC-MS/MS determination of the selected antibiotic substances, test tubes were spiked with a standard solution of the substances.

Based on this evaluation, a number of the investigated substances had to be excluded. The major reasons for exclusion of substances were either poor chromatography, with inadequate separation, or poor peak shapes, resulting in too low sensitivity. Unsatisfactory mass spectrometric resolution was another reason for exclusion. The excluded substances were mainly different penicillins (e.g., Amoxicillin, Benzylpenicillin, Cloaxcillin), as well as Ceftadizim, Cefuroxim, and Vancomycin. In three instances (Cefotaxim, Imipenem and 
Meropenem), although possible to analyze, the analysis did not give a low enough quantification level for the desired performance of the screening method.

Twelve substances (see Table 3) were found to meet the basic criteria, i.e., be possible to analyze in the same run at an analytical detection limit (ADL) adequate for screening with wipe samples from $100 \mathrm{~cm}^{2}$ surfaces. All substances, except Demeclocyklin $\mathrm{HCl}$ and Doxycyklin, showed recoveries above 70\%. The RSD was below 30\% for all substances except Ciprofloxacin and Norfloxacin. The recovery tests were carried out at levels within two orders of magnitude above the ADL. This performance was considered adequate for a screening method.

Figure 2 shows a chromatogram with all twelve substances included in the screening method. All substances could be separated within a 12 min chromatographic run. In the chromatogram, based on the total ion current, only ten peaks appear. Metronidazol, Norfloxacin and Ofloxacin were found to have the same retention time. These substances have, however, different pre-cursor and daughter ions (see Table 2) and could efficiently be resolved via MS/MS fragmentation and be quantified individually although having the same retention time.

\section{Detection limits}

The ADL, defined as three times the background noise, for the selected substances and the surface detection limits (SDL), based on a $100 \mathrm{~cm}^{2}$ wipe sample, are listed in Table 4 . The ADL for the substances in the screening method ranged from $0.3-3 \mathrm{ng} / \mathrm{sample}$. The lowest ADL was obtained for Norfloxacin and the highest for Metronidazol. The SDL, expressed as $\mathrm{ng} / \mathrm{cm}^{2}$, will, however, vary depending on the area size of the wiped surface, i.e. the larger size of wiped surface area the lower SDL can be obtained. With a surface area size of 100 $\mathrm{cm}^{2}$, the obtained SDLs were fully satisfactory for the desired performance of the screening method. 


\section{Validation of the screening method}

This method is intended for supervisory screening and other performance criteria, such as simplicity, robustness and high sampling efficiency also have high priority, besides the analytical performance. In the judging method utility, focus has been put on the number of substances that can be analyzed simultaneously at an SDL corresponding to a surface level of $0.05 \mathrm{ng} / \mathrm{cm}^{2}$ or lower. The described method has been validated in this context.

The recoveries and reproducibility of wipe sampling antibiotic substances from various commonly occurring surface materials were investigated. Surfaces of glass, stainless steel, plastic floor carpet and laminate bench top were spiked with known amounts of antibiotic substances in the range of $0.4-3 \mathrm{ng} / \mathrm{cm}^{2}$. In this experiment, all spikings were made in triplicate and left to dry before the wipe samples were collected. The spiking experiment was also repeated on a later occasion, and, thus, resulting in two set of triple replicates for each surface material.

The result of the recovery and reproducibility study is presented in Table 5 . The mean relative recovery was calculated from all six spiking made at two different occasions on each surface material. Considering that this is intended as a screening method, good performance was obtained for Cefadroxil, Cefalexin, Flukonazol, Metronidazol on all four surface materials and for Diaveridin and Trimetoprim on three surface materials (glass, stainless steel and bench top laminate). Acceptable performance was obtained for Enrofloxacin, Norfloxacin on all surface materials, for Ciprofloxacin, Ofloxacin on three surface materials (glass, stainless steel and bench top laminate) and for Diaveridin and Trimetoprim on one surface material (plastic floor carpet). Although not fully acceptable, useful performance for a screening method was obtained for Ciprofloxacin and Ofloxacin on one surface material (plastic floor carpet). For Doxycyklin, a useful screening performance was obtained only for two surface materials (bench top laminate and glass), but not for the other surface materials. Finally, it can be questioned if the performance for Demeclocyklin $\mathrm{HCl}$ can be regarded as useful for any surface material.

For all substances, the lowest recoveries were obtained from the plastic floor carpet. Many plastic materials show sorption properties [19-20]. These properties will increase the adhesion of organic compounds to the material and may explain the lower recoveries for wipe sampling 
on plastic floor carpet. This effect may also have a negative impact on the cleaning efficiency of floors covered with plastic carpets.

For practical use of a screening method, in order to get a reasonable overview and be able to compare the level of contamination, it can be appropriate to classify the samples into different categories. Each sample can be given a score from the results according to the following parameters: i) the number of found substances (one point for each substance), ii) the level of the substances. A suitable scoring for each substance is a level of not detected to 0.1 $\mathrm{ng} / \mathrm{cm}^{2}=1$ point; $0.1-0.5 \mathrm{ng} / \mathrm{cm}^{2}=2$ points; $0.5-1.0 \mathrm{ng} / \mathrm{cm}^{2}=3$ points; $1-2 \mathrm{ng} / \mathrm{cm}^{2}=4 ; 2-5$ $\mathrm{ng} / \mathrm{cm}^{2}=5 ; 5-10 \mathrm{ng} / \mathrm{cm}^{2}=6 ;>10 \mathrm{ng} / \mathrm{cm}^{2}=7$. A high score, thus, means a large contamination. The range of points from the lowest to the highest scored sample can then be divided into four ranges of equal numerical size, representing the four categories: Low, Medium, High and Very high level of contamination.

Based on the individual score, each sample can then be classified into one of the contamination categories. If several samples are collected at the same site, the scores can be combined for classification of the contamination level at the site. This classification model, where the results are grouped into concentration ranges, will also contribute to decrease the effects of any deficiencies in the recovery performance for some of the substances and surface material. For example, if the true level of a substance is $0.4 \mathrm{ng} / \mathrm{cm}^{2}$ and the recovery is $60 \%$, the analysis will show $0.24 \mathrm{ng} / \mathrm{cm}^{2}$. Both these values will fall into the same group and get the same score. However, if the true level of the substance is $0.15 \mathrm{ng} / \mathrm{cm}^{2}$ the analysis will show $0.09 \mathrm{ng} / \mathrm{cm}^{2}$. Here, the analytical result will fall into the lower group and the sample would be scored too low. Only samples those true values are close to the lower border of a group would risk to be scored too low due to deficiency in analytical performance.

\section{Conclusions}

The developed HPLC-MS/MS method has been proven to be suitable for analysis of the twelve selected antibiotic substances in solutions from extracted wipe samples, collected from frequently occurring surface materials. All substances can be separated and quantified simultaneously in one analysis. The obtained ADLs were satisfactory for all twelve selected 
substances and, based on a $100 \mathrm{~cm}^{2}$ wipe sample, SDLs well below the desired level were obtained for all substances. For screening investigations using collections of wipe samples, a good or acceptable performance was obtained for ten substances on most surface materials. Although not fully acceptable, useful performance for a screening method was obtained for almost all substances on all surface materials. For comparison of the screening results, a classification procedure can be employed, where each sample gets a score depending on the number of substances found the concentration level in the sample. The samples can then be divided into four groups representing increasing contamination. Such classification simplifies comparisons and will also circumvent any deficiency of recovery performance for some substances and surface materials.

\section{Acknowledgement}

Arbetslivets Försäkringsaktiebolag (AFA) [Work Life Insurance Inc] is acknowledged for the financial support that made this study possible.

\section{References}

1. NIOSH. Workplace Safety \& Health Topics: Occupational Exposure to Antineoplastic Agents. National Institute for Occupational Safety and Health, Cincinnati, US, 2010. See URL: http://www.cdc.gov/niosh/topics/antineoplastic/default.html.

2. CSHP Guidelines for the handling and disposal of hazardous pharmaceuticals (including anti-cancer drugs), Canadian Society of Hospital Pharmacists, Ottawa, 1993.

3. American Society of Health-System Pharmacists. ASHP Guidelines on Handling Hazardous Drugs. Am J of Health-Syst Pharm. 63 (2006), 1172-1193.

4. HSE. Information Sheet MISC 615. Safe handling of cytotoxic drugs. Health and Safety Executive, Sudbury, Suffolk CO10 2WA, U.K., 2003.

See URL: http://www.hse.gov.uk/pubns/misc615.pdf

5. Work Health Authority. Ordinance AFS 2005:5. Cytostatics and other drugs with persistent toxic effects. Swedish Work Health Authority, Stockholm, Sweden, 2005. 
6. Apoteket. Försäljningsstatistik [Sale statistics]. (in Swe) Apoteket AB, Stockholm. 2010. See URL: http://www2.apoteket.se/om/VadViGor/Forsalj/default.htm.

7. Lindberg R. Determination of Antibiotics in the Swedish Environment with Emphasis on Sewage Treatment Plants. ISBN 91-7264-045-6. Dissertation, Umeå University, Umeå, Sweden 2006.

8. Niessen W M A. Analysis of antibiotics by liquid chromatography-mass spectrometry. J Chromatogr A 812 (1998), 53-75.

9. Sessink P J M, Anzion R B, Van den Broek P H H, Bos R P. Detection of contamination with antineoplastic agents in a hospital pharmacy department. Pharm Weekbl (Sci) 14 (1992), 16-22.

10. Tuerk J, Reinders M, Dreyer D, Kiffmeyer T K, Schmidt K G, Kuss H-M. Analysis of antibiotics in urine and wipe samples from environmental and biological monitoring Comparison of HPLC with UV-, single MS- and tandem MS-detection. J Chromatogr B 831 (2006), 72-80.

11. Hedmer M, Jönsson B A, Nygren O. Development and validation of methods for environmental monitoring of cyclophosphamide in workplaces. J Environ Monit 6 (2004), 979-84.

12. Minoia C, Turci R, Sottani C, Schiavi A, Perbellini L, Angeleri S, Draicchio F, Apostoli P. Application of high performance liquid chromatography/tandem mass spectrometry in the environmental and biological monitoring of health care personnel occupationally exposed to cyclophosphamide and ifosfamide. Rapid Commun Mass Spectrom 12 (1998), 1485-1493.

13. Nygren O, Lundgren C. Determination of platinum in workroom air and in blood and urine from nursing staff working with patients receiving cisplatin chemotherapy. Int Arch Occup Environ Health 70 (1997), 209-214.

14. Ensslin S, Pethran A, Schierl R, Fruhmann G. Urinary platinum in hospital personnel occupationally exposed to platinum-containing antineoplastic drugs. Int Arch Occup Environ Health 65 (1994), 339-42.

15. Nygren O, Aspman O. Validation and application of wipe sampling and portable XRF analysis as an on-site screening method for assessment of deposited aerosols on workplaces, Aust J Chem 37 (2004), 1021-28. 
16. Nygren O. Wipe sampling as a tool for monitoring aerosol deposition in workplaces. $J$ Environ Monit 8 (2006), 49 - 52.

17. FASS. Farmaceutiska Specialiteter i Sverige [Pharmaceutical Specialites in Sweden]. (in Swe) Läkemedelsinsdustriföreningen, Stockholm, 2010. See URL: http://www.fass.se.

18. Nygren O, Lindahl R. Screening of spill and leakage of antibiotics in hospital wards. Journal of ASTM International, submitted 2010.

19. Berens A R. Transport of organic vapors and liquids in polyvinyl(chloride) Makromol. Chem., Macromol. Symp. 29 (1989), 95- 108

20. Saquing J M, Saquing C D, Knappe D R U, and Barlaz M A. Impact of Plastics on Fate and Transport of Organic Contaminants in Landfills. Environ. Sci. Technol. 44 (2010), 6396-6402 


\section{Tables}

Table 1. The antibiotic substances (in alphabetic order) considered for the method.

The trivial names and spelling are given according to FASS [17]. CA - could not be analysed (poor chromatography or unsatisfactory MS resolution); TLS - too low sensitivity

\begin{tabular}{lcl}
\hline Antibiotic substance & $\begin{array}{c}\text { I=Included; } \\
\text { R=Rejected }\end{array}$ & Comment \\
\hline Amoxicillin & $\mathrm{R}$ & $\mathrm{CA}$ \\
Benzylpenicillin & $\mathrm{R}$ & $\mathrm{CA}$ \\
Cefadroxil & $\mathrm{I}$ & \\
Cefalexin & $\mathrm{I}$ & \\
Cefotaxim & $\mathrm{R}$ & $\mathrm{TLS}$ \\
Ceftadizim & $\mathrm{R}$ & $\mathrm{CA}$ \\
Cefuroxim & $\mathrm{R}$ & $\mathrm{CA}$ \\
Ciprofloxacin & $\mathrm{I}$ & \\
Demeclocykline HCl & $\mathrm{I}$ & \\
Diaveridin & $\mathrm{I}$ & \\
Doxycyklin & $\mathrm{I}$ & \\
Enrofloxacin & $\mathrm{I}$ & \\
Flukonazol, & $\mathrm{I}$ & \\
Gentamicin & $\mathrm{R}$ & $\mathrm{CA}$ \\
Imipenem & $\mathrm{R}$ & $\mathrm{TLS}$ \\
Klindamycin & $\mathrm{R}$ & $\mathrm{CA}$ \\
Meropenem & $\mathrm{R}$ & $\mathrm{TLS}$ \\
Metronidazol & $\mathrm{I}$ & \\
Norfloxacin & $\mathrm{I}$ & \\
Ofloxacin & $\mathrm{I}$ & \\
Penicillins, e.g., Kloaxcillin & $\mathrm{R}$ & $\mathrm{CA}$ \\
Piperacillin/Tazobaktam & $\mathrm{R}$ & $\mathrm{CA}$ \\
Pivmecillinam & $\mathrm{R}$ & $\mathrm{CA}$ \\
Tobramycin & $\mathrm{R}$ & $\mathrm{CA}$ \\
Trimetoprim & $\mathrm{R}$ & $\mathrm{CA}$ \\
Vancomycine & & \\
\hline
\end{tabular}


Table 2. MS/MS settings.

The trivial names and spelling are given according to FASS [17]. Q1 is the precursor ion and Q3 the product ion masses. DP-declustering potential, FP-focusing potential, EP-entrance potential, CEP-collision cell entrance potential, CXP-collision cell exit potential, CE-collision energy.

\begin{tabular}{lcccccccc}
\hline & $\begin{array}{c}\text { Q1 } \\
\mathrm{m} / \mathrm{z}\end{array}$ & $\begin{array}{c}\text { Q3 } \\
\mathrm{m} / \mathrm{z}\end{array}$ & DP & FP & EP & CEP & CXP & CE \\
& & & & & & & & \\
\hline Cefadroxil & 364 & 208 & 6 & 370 & 5 & 24 & 4 & 17 \\
Cefalexin & 348 & 158 & 1 & 360 & 5,5 & 20 & 2 & 21 \\
Ciprofloxacin & 332 & 288 & 101 & 330 & 4,5 & 22 & 8 & 19 \\
Demeclocyklin HCl & 465 & 448 & 21 & 370 & 8,5 & 18 & 4 & 27 \\
Diaveridin & 261 & 245 & 16 & 370 & 8 & 26 & 10 & 25 \\
Doxycyklin & 445 & 428 & 31 & 370 & 10 & 20 & 4 & 33 \\
Enrofloxacin & 360 & 316 & 16 & 370 & 5,5 & 28 & 10 & 27 \\
Flukonazol & 307 & 220 & 26 & 320 & 9 & 22 & 6 & 27 \\
Metronidazol & 172 & 154 & 26 & 370 & 6 & 26 & 4 & 23 \\
Norfloxacin & 320 & 276 & 21 & 370 & 7 & 18 & 4 & 27 \\
Ofloxacin & 362 & 318 & 26 & 370 & 8,5 & 22 & 4 & 25 \\
Trimetoprim & 291 & 230 & 36 & 370 & 8,5 & 20 & 4 & 33 \\
\hline
\end{tabular}


Table 3. Analytical recovery of the selected substances.

Mean recovery of four test samples, RSD-Relative standard deviation; The trivial names are given according to FASS [17].

\begin{tabular}{lrrr} 
Substance & Spike $(\mathbf{n g})$ & Recovery $(\%)$ & RSD $(\%)$ \\
\hline Cefadroxil & 179 & 95 & 9 \\
Cefalexin & 292 & 96 & 5 \\
Ciprofloxacin & 43 & 99 & 43 \\
Demeclocyklin HCl & 131 & 42 & 27 \\
Diaveridin & 89 & 80 & 13 \\
Doxycyklin & 133 & 62 & 29 \\
Enrofloxacin & 50 & 75 & 26 \\
Flukonazol & 39 & 93 & 2 \\
Metronidazol & 102 & 102 & 6 \\
Norfloxacin & 57 & 105 & 34 \\
Ofloxacin & 58 & 94 & 25 \\
Trimetoprim & 120 & 70 & 17 \\
\hline
\end{tabular}


Table 4. Analytical detection limits $(A D L)$ and surface detection limit (SDL), based on a $100 \mathrm{~cm}^{2}$ wipe sample, for the antibiotic substances determined in the screening method The trivial names are given according to FASS [17].

\begin{tabular}{lcl}
\hline Substance & $\begin{array}{c}\text { ADL } \\
(\mathbf{n g} / \mathbf{s a m p l e})\end{array}$ & $\begin{array}{c}\text { SDL } \\
\left(\mathbf{n g} / \mathbf{c m}^{2}\right)\end{array}$ \\
\hline Cefadroxil & 0.50 & 0.005 \\
Cefalexin & 3.00 & 0.03 \\
Ciprofloxacin & 0.50 & 0.005 \\
Demeclocykline HCl & 2.00 & 0.02 \\
Diaveridin & 1.00 & 0.01 \\
Doxycyklin & 2.00 & 0.02 \\
Enrofloxacin & 0.30 & 0.003 \\
Flukonazol & 0.70 & 0.007 \\
Metronidazol & 3.00 & 0.03 \\
Norfloxacin & 0.30 & 0.003 \\
Ofloxacin & 0.40 & 0.004 \\
Trimetoprim & 2.00 & 0.02 \\
\hline
\end{tabular}


Table 5. Recovery of antibiotic substances from different surface materials.

Mean recovery (in \%) of six samples for each surface material with relative standard deviation (in \%). Rec - recovery; RSD - relative standard deviation. The trivial names are given according to FASS [17].

\begin{tabular}{|c|c|c|c|c|c|c|c|c|c|}
\hline \multirow[t]{3}{*}{ Substance } & \multirow{3}{*}{$\begin{array}{c}\text { Spike } \\
\mathrm{ng} / \mathrm{cm}^{2}\end{array}$} & \multicolumn{8}{|c|}{ Surface material } \\
\hline & & \multicolumn{2}{|c|}{ Bench } & \multicolumn{2}{|c|}{ Glass } & \multicolumn{2}{|c|}{ Plastic floor carpet } & \multicolumn{2}{|c|}{ Stainless steel } \\
\hline & & $\operatorname{Rec}$ & RSD & $\operatorname{Rec}$ & RSD & $\operatorname{Rec}$ & RSD & Rec & RSD \\
\hline Cefadroxil & 1.8 & 71 & 12 & 90 & 17 & 77 & 13 & 87 & 16 \\
\hline Cefalexin & 2.9 & 94 & 17 & 118 & 12 & 77 & 5 & 122 & 10 \\
\hline Ciprofloxacin & 0.4 & 50 & 42 & 59 & 32 & 19 & 66 & 37 & 35 \\
\hline Demeclocyklin $\mathrm{HCl}$ & 1.3 & 6 & 86 & 5 & 65 & 3 & 62 & 5 & 100 \\
\hline Diaveridin & 0.9 & 87 & 12 & 144 & 19 & 34 & 12 & 149 & 9 \\
\hline Doxycyklin & 1.3 & 14 & 34 & 10 & 101 & 6 & 35 & 6 & 36 \\
\hline Enrofloxacin & 0.5 & 30 & 38 & 53 & 20 & 17 & 35 & 37 & 24 \\
\hline Flukonazol & 0.4 & 84 & 3 & 98 & 6 & 81 & 9 & 99 & 5 \\
\hline Metronidazol & 1.0 & 101 & 23 & 103 & 16 & 78 & 12 & 110 & 9 \\
\hline Norfloxacin & 0.6 & 48 & 61 & 52 & 26 & 34 & 24 & 32 & 36 \\
\hline Ofloxacin & 0.6 & 39 & 30 & 56 & 26 & 19 & 21 & 42 & 19 \\
\hline Trimetoprim & 1.2 & 67 & 9 & 106 & 21 & 31 & 6 & 113 & 12 \\
\hline
\end{tabular}




\section{Figures}

Figure 1. Substances included in the screening method.

Structural formulas, trivial and chemical names are given according to FASS [17].

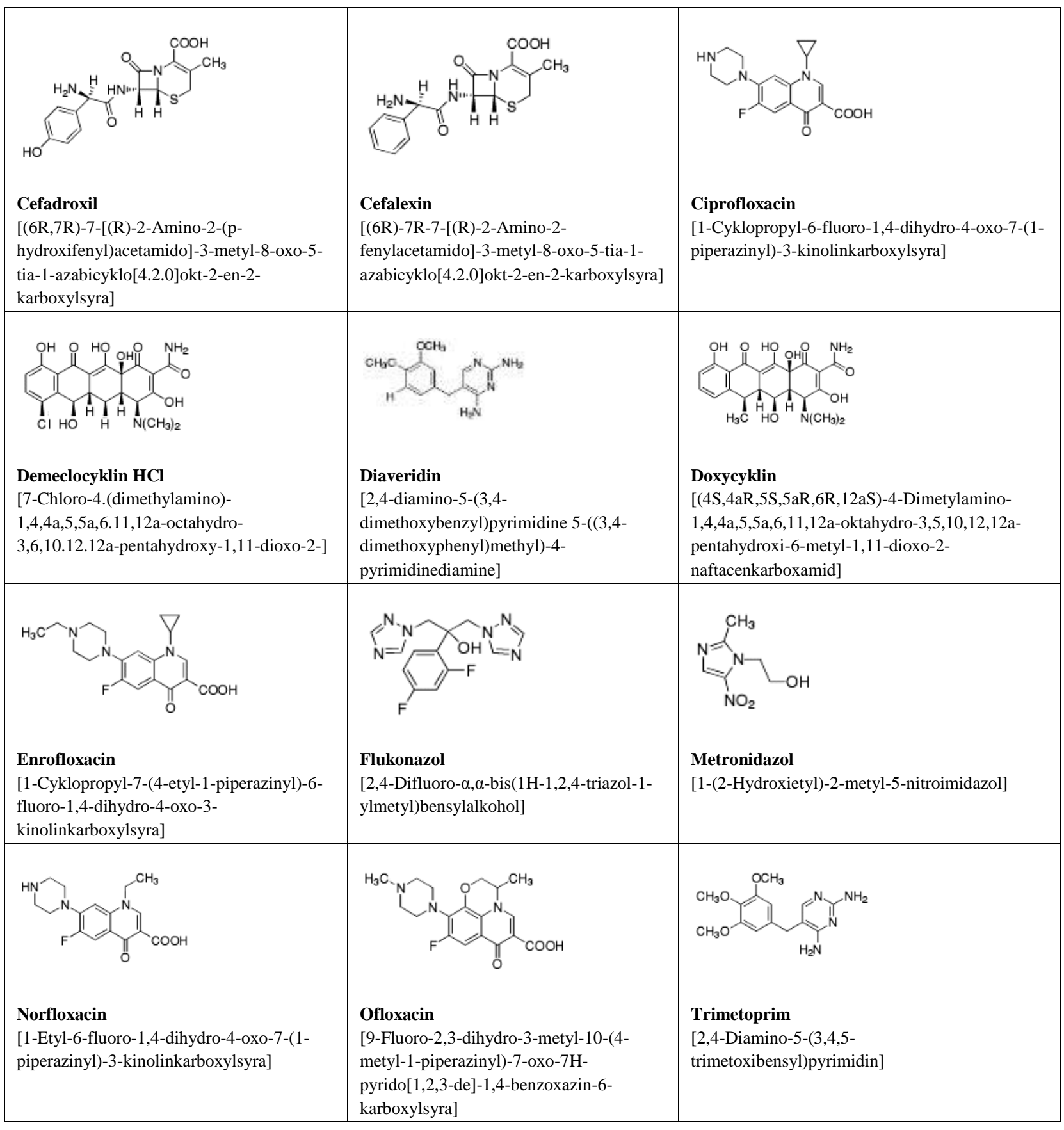


Figure 2. Chromatogram of all twelve substances.

The chromatogram shows the total ion current (TIC) of all masses. The substances are ACefadroxil; B-Diaveridin; C-Trimetoprim; D-Cefalexin; E-Ofloxacin, Norfloxacin and Metronidazol; F-Ciprofloxacin; G-Enrofloxacin; H-Demeklocyklin HCl; I-Doxycyklin; J-

Flukonazol. The solid line between peak $\mathrm{G}$ and $\mathrm{H}$ marks a change in scan parameters (see the text for details).

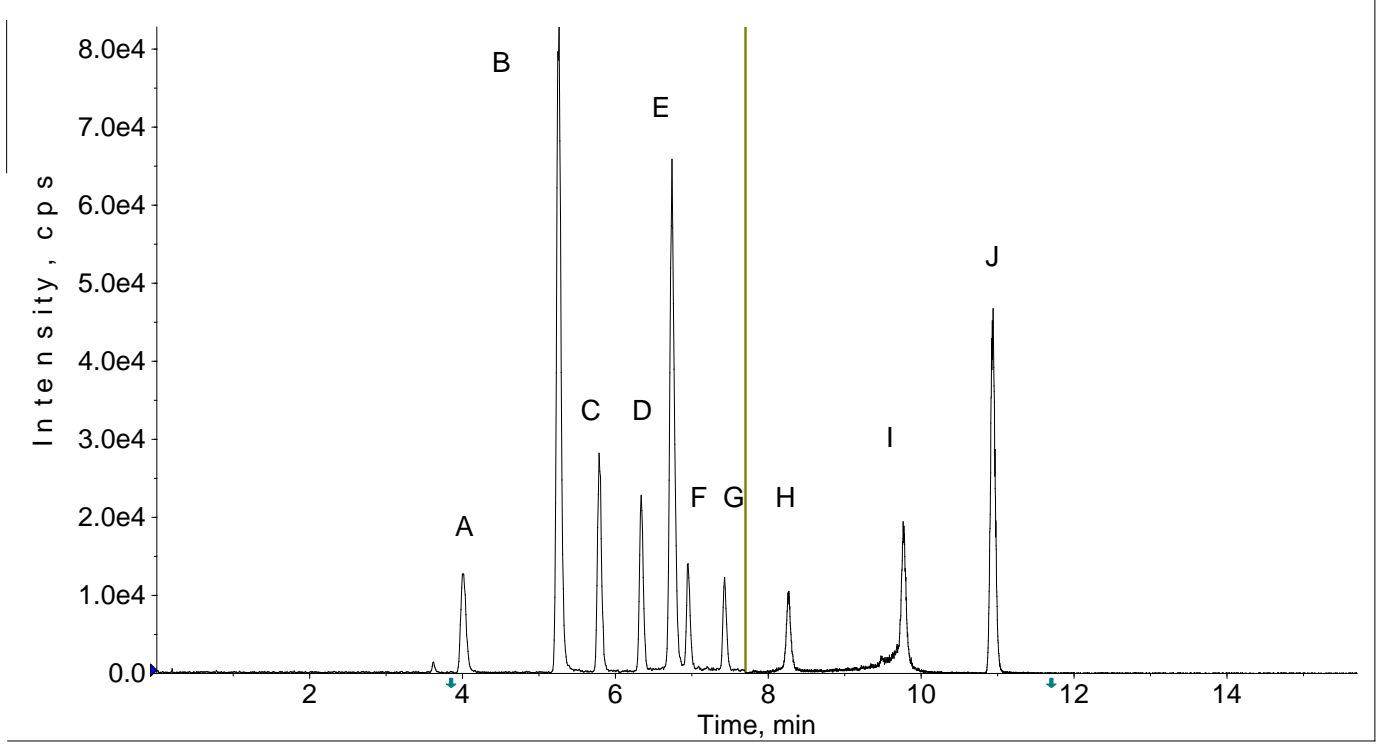

